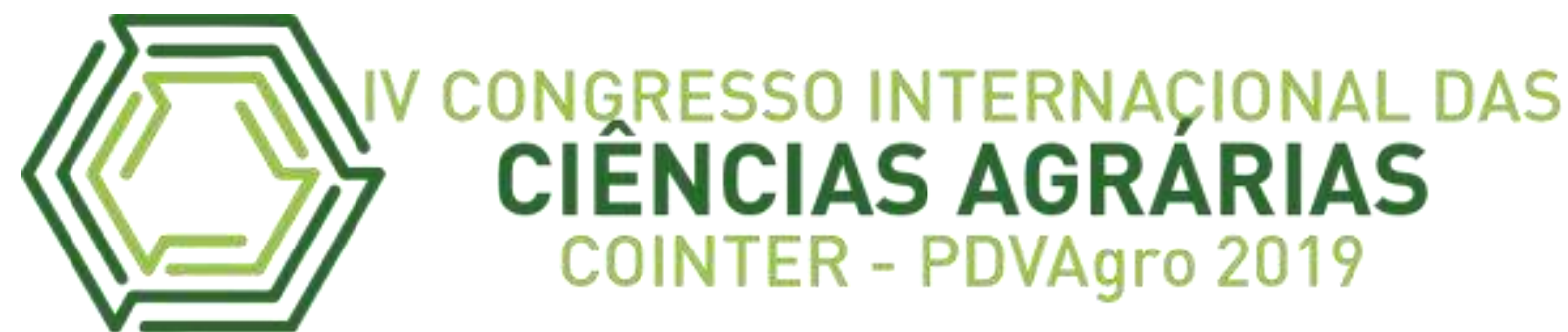

\title{
MONITORAMENTO DA PROSPECÇÃO CIENTÍFICA E TECNOLÓGICA DA BABOSA
}

\author{
Apresentação: Comunicação Oral \\ Rayane Amorim Carvalhoํㅜ Álvaro Itaúna Schalcher Pereira ${ }^{2}$; Oswaldo Palma Lopes \\ Sobrinho $^{3}$; Francisco Adelton Alves Ribeiro ${ }^{4}$
}

DOI: https://doi.org/10.31692/2526-7701.IVCOINTERPDVAgro.2019.0005

\begin{abstract}
Resumo
A espécie Aloe vera (L.) conhecida popularmente como babosa, Erva-babosa, Erva-de-azebre, Caraguatá e Caraguatá-de-jardim é uma planta pertencente ao gênero Aloe e família das Liliáceas. Tem sido muito utilizada como um recurso terapêutico desde os primórdios da Antiguidade devido a sua importância na esfera farmacológica, química e biológica. Este trabalho teve por objetivo realizar o monitoramento científico e tecnológico desta espécie com o intuito de fazer um mapeamento de seu progresso no campo científico e tecnológico. Para tanto, foram empregadas técnicas de prospecção científica e tecnológica, usando as bases de dados Scopus e World Intellectual Property Organization (WIPO) como banco de dados. De posse dos dados da pesquisa foi constatado que a Índia é detentora do maior número de publicações de artigos científicos, enquanto que os Estados Unidos foi o responsável pelo maior número de patentes depositadas envolvendo a espécie babosa. O grau de interesse científico diminuiu ao longo dos anos, assim como o tecnológico, evidenciados pelo baixo número de artigos e patentes nos últimos anos, respectivamente. O Brasil apesar de ser referência em pesquisas de produtos naturais apresentou uma baixa produção científica e tecnológica quando comparado a outros países. As áreas que envolvem mais estudos sobre a espécie são a medicina e farmacologia/toxicologia. As suas principais propriedades biológicas mais citadas foram cicatrizante, antioxidante e antimicrobiana. Quanto à CIP, a subclasse mais categorizada foi a $\mathrm{A} 61 \mathrm{~K}$, apontando para o maior uso da Aloe vera no desenvolvimento de produtos com finalidades médicas e odontológicas.
\end{abstract}

Palavras-chave: Aloe vera, artigos científicos, patentes.

\footnotetext{
Abstract

The Aloe vera (L.) species popularly known as Aloe Vera, Aloe Vera, Jellybean, Caraguatá and Garden Caraguatá is a plant belonging to the genus Aloe and family of Lilies. It has been

${ }^{1}$ Licenciada em Ciências Agrárias, Instituto Federal do Maranhão - Campus Codó (IFMA). E-mail: rayane_gts8@hotmail.com

2 Professor Doutor, Orientador, Instituto Federal do Maranhão - Campus Codó (IFMA). E-mail: alvaro.pereira@ifma.edu.br

${ }^{3}$ Engenheiro Agrônomo pelo IFMA/Campus Codó, Mestrando em Ciências Agrárias - Agronomia, Instituto Federal Goiano - Campus Rio Verde (IF Goiano). E-mail: oswaldo-palma@ hotmail.com

4 Professor Doutor, Coorientador, Instituto Federal do Maranhão - Campus Codó (IFMA). E-mail: adelton@ifma.edu.br
} 
widely used as a therapeutic resource since ancient times due to its importance in the pharmacological, chemical and biological sphere. This work aimed to carry out scientific and technological monitoring of this species in order to map its progress in the scientific and technological field. To this end, scientific and technological prospecting techniques were employed, using the Scopus and World Intellectual Property Organization (WIPO) databases as databases. In possession of the survey data it was found that India has the largest number of publications of scientific articles, while the United States was responsible for the largest number of patents filed involving the aloe species. The degree of scientific interest has decreased over the years, as well as the technological interest, evidenced by the low number of articles and patents in recent years, respectively. Despite being a reference in natural products research, Brazil presented a low scientific and technological production when compared to other countries. Areas that involve further studies on the species are medicine and pharmacology/toxicology. Its main biological properties most mentioned were healing, antioxidant and antimicrobial. Regarding CIP, the most categorized subclass was the A61K, pointing to the greater use of Aloe vera in the development of products for medical and dental purposes.

Keywords: Aloe vera, scientific articles, patents.

\section{Introdução}

A espécie Aloe vera é conhecida no Egito antigo como a "planta da imortalidade", ela teria sido usada por Cleópatra nos cuidados da pele e do cabelo (FEITAS; RODRIGUES; GASPI, 2014). É uma planta que consegue desenvolver seu crescimento naturalmente em climas secos e quentes. Em sua composição, é constituída pelo tecido chamado mucilagem, que é composto aproximadamente por $98 \%$ de água, e $2 \%$ de outros compostos 75 bioativos (flavonóides, saponinas, esteróides, aminoácidos, sais minerais, vitaminas, etc.), cujas concentrações podem variar de acordo com as espécies, assim como com as condições de crescimento e clima (PARENTE et al., 2013).

Assim, diversas são as atividades biológicas evidenciadas pela Aloe vera, dentre as quais podem ser citadas as atividades de conservação de alimentos, de clareamento da pele, potencial antimicrobiano, imunomoduladora, hepatoprotetora, hipoglicemiante, antitumoral, antioxidante, anti-inflamatória, nefroprotetora, cicatrizante de feridas e de queimaduras (BACH; LOPES, 2007; PATROCÍNIO; MACILHIA, 2012). Inclusive seu uso também é reportado na grande área das Ciências Agrárias.

Os estudos de prospecção são importantes, porém ainda são poucos explorados no Brasil. Neste aspecto, conforme Pereira et al. (2015), as bases de artigos científicos e patentes vem se apresentando como ricas fontes de informações científicas e tecnológicas. As mesmas podem ser acessadas a todo momento de qualquer parte do mundo, o que facilita na 
recuperação dos dados. Diante do exposto, objetivou-se realizar uma prospecção científica e tecnológica relacionadas à espécie Aloe vera, nas bases de dados Scopus e WIPO a fim de mapear as produções científicas e tecnológicas.

\section{Metodologia}

O presente trabalho trata-se de um estudo de caso, pois consiste no estudo profundo e exaustivo de um objeto de estudo, de maneira que permita seu amplo e detalhado conhecimento (GIL, 2002). Trata-se de uma pesquisa descritiva, pois tem como objetivo primordial a descrição das características de determinado fenômeno, bem como o estabelecimento de relações entre variáveis existentes. E também classifica-se, como explicativa, uma vez que, busca identificar os fatores que determinam ou que contribuem para a ocorrência dos fenômenos.

A metodologia constitui-se de um processo continuo, pois, a mesma contempla a prospecção científica e tecnológica da espécie Aloe vera. Na prospecção científica foram analisados os dados da base científica Scopus, que é a maior base de dados de resumos e citações de literatura revisada por pares, com ferramentas bibliométricas para acompanhar, analisar e visualizar a pesquisa. A Scopus conforme a Coordenação de Aperfeiçoamento de Pessoal de Nível Superior (CAPES) contém mais de 22.000 títulos de mais de 5.000 editores em todo o mundo, abrangendo as áreas de Ciência, Tecnologia, Medicina, Ciências Sociais e Artes e Humanidades (CAPES, 2016). Na recuperação das informações científicas utilizou-se a palavra-chave Aloe vera, sendo considerados os artigos que apresentaram este termo no título e/ou resumo. Os artigos encontrados foram quantificados e analisados sob diferentes aspectos, a saber: distribuição de artigos científicos por países, por ano e por área de conhecimento.

Enquanto que na prospecção tecnológica foram analisados os dados da base WIPO. De forma análoga, na prospecção tecnológica foram recuperados documentos de patentes utilizando a palavra-chave Aloe vera, sendo considerados os documentos que apresentaram este termo no título e/ou resumo. Os documentos de patentes encontrados foram quantificados e para melhor análise foram distribuídos em patentes depositadas por países, por ano e por Classificação Internacional de Patentes (CIP).

Os dados foram organizados em gráficos e tabelas para melhor exposição dos dados. Para isso foram utilizadas planilhas do Microsoft Word e Excel versão 2016. A pesquisa 
bibliográfica foi desenvolvida baseada em materiais já publicados constituídos principalmente de artigos científicos, monografias, dissertações, teses, livros e sites especializados. Os documentos bibliográficos foram selecionados de acordo com a relação com o objeto de estudo e analisados para a contextualização teórica do problema, revelando contribuições anteriores para o este estudo.

\section{Resultados e Discussões}

Os artigos científicos foram analisados quanto aos países, anos de publicação e áreas de conhecimentos. De acordo com a Figura 1, os países que apresentaram a maior produção de artigos científicos foi a Índia, com cerca de 2.936 artigos científicos publicados, seguido dos Estados Unidos com 1.468 artigos científicos, a China e Irã, com 1.155 e 794 artigos publicados, respectivamente. O Brasil fica na quinta colocação com apenas 511 artigos científicos publicados.

Figura 1: Produção de artigos científicos por países da espécie Aloe vera.

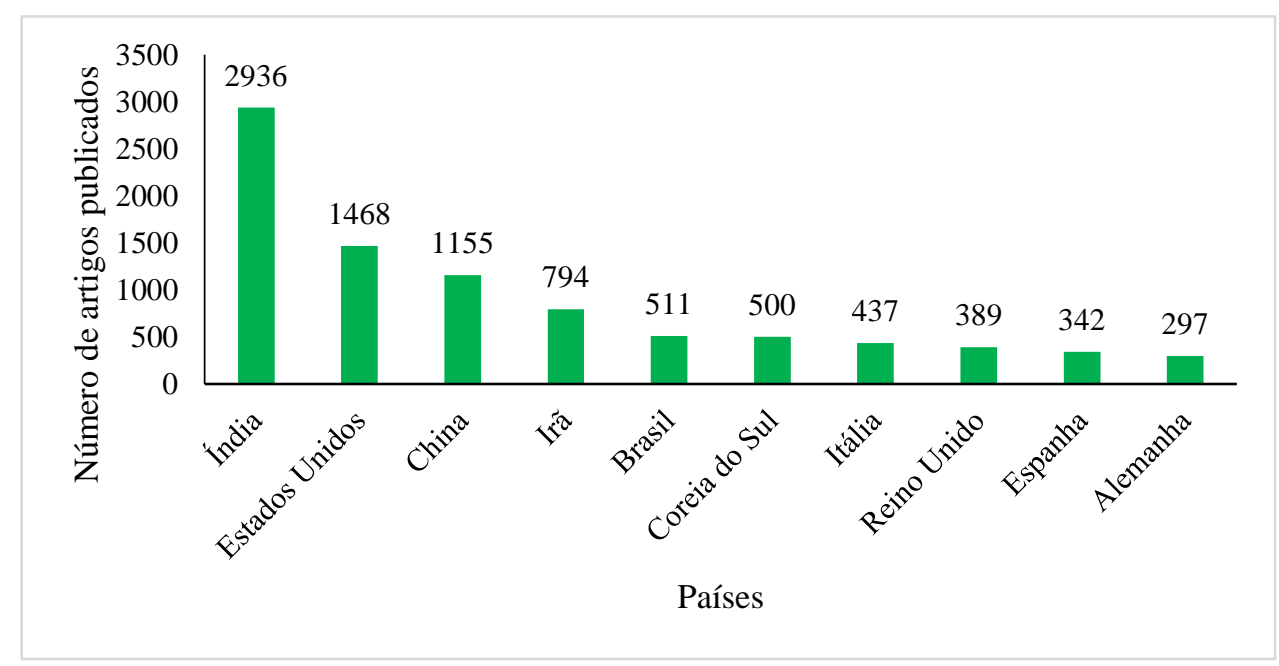

Fonte: Própria (2019)

De acordo com isso, percebe-se a liderança da Índia nas publicações científicas da espécie Aloe vera. O país asiático segue uma trajetória de crescimento em suas pesquisas científicas, parte desse sucesso indiano vem dos altos investimentos em inovação e da participação da iniciativa privada no desenvolvimento de tecnologias envolvendo a espécie Aloe vera. A Índia tem aumentado significativamente seu potencial mundial, o que a faz possuir uma potencialidade capaz de transformar o seu conhecimento científico em produtos. Como um país em pleno desenvolvimento, à medida que a Índia desenvolve sua iniciativa científica, diversifica a sua base de pesquisa e expandem suas redes colaborativas, a nação 
está bem posicionada para se tornar uma das líderes da ciência no mundo. No caso, o país se destaca em pesquisa de fármacos, química, engenharia química e ciência dos materiais havendo um grande interesse daquele país pelas pesquisas sobre a Aloe vera.

Os Estados Unidos, na segunda colocação, apresenta notoriedade nessa área de pesquisa. A inovação tecnológica no país é muito forte, haja vista que consegue investir fortemente no desenvolvimento de tecnologias envolvendo a Aloe vera, seja no desenvolvimento de fármacos e derivados como na produção de produtos cosméticos. O país é responsável também por grandes investimentos em pesquisa e desenvolvimento de novos produtos em outros países. Já o Brasil apesar de ser considerado um dos países mais importantes na pesquisa em produtos naturais, apresentou um número pouco expressivo, dada sua relevância nessa área. Ocupando a quinta posição no ranking, o país também possui produtos à base de Aloe vera.

A Figura 2 retrata a trajetória anual da publicação de artigos nos últimos dez anos. Assim, é mostrado que o ano que mais houve publicações foi em 2016 com 1.710 artigos científicos, seguido 2015 e 2014, com 1.472 e 1.350 artigos publicados, respectivamente.

Figura 2: Distribuição de artigos por ano da espécie Aloe vera.

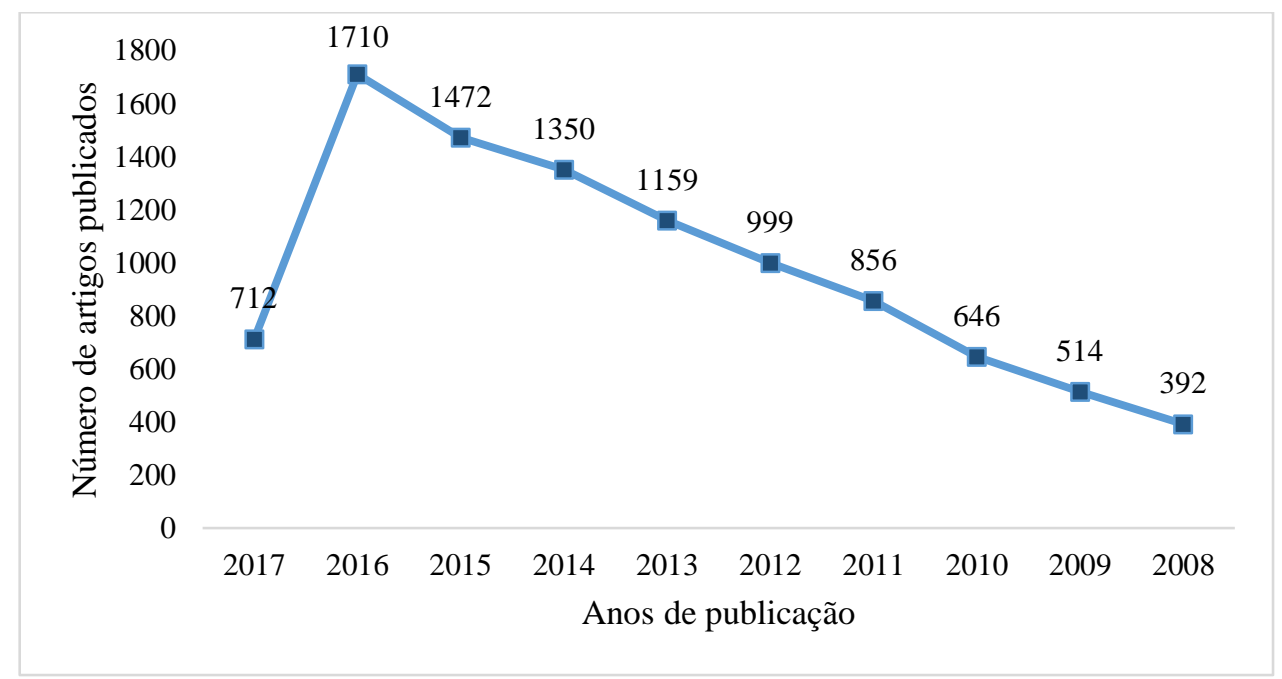

Fonte: Própria (2019)

Observa-se uma tendência na taxa de crescimento e artigos publicados ao longo de dez anos. Há um crescimento gradual em relação aos números de artigos, atingindo seu ápice no ano de 2016. Essa tendência permite concluir que o interesse científico na espécie estudada vem crescendo cada vez mais, o que comprova a importância dessa planta, sendo que a mesma possui inúmeras propriedades farmacológicas como antibacteriana, anti-inflamatória, 
cicatrizante, antioxidantes, atuando no controle da glicemia, tuberculose, angiogênese, fibrose hepática e neoplasias (SOTILLI, 2015).

O uso e aplicação da espécie Aloe vera nas áreas da Medicina, Ciências Biológicas, Química, Farmacologia e etc., demonstram sua versatilidade e, consequentemente, sua popularidade no meio científico. Conforme visto na Figura 3, a medicina trata-se da área mais produtiva em termos de artigos científicos envolvendo a espécie Aloe vera, com um total de 4.163. A segunda área de conhecimento mais representativa é a Farmacologia e Toxicologia com 2.884 artigos publicados, em seguida a Agricultura e Ciências com 2.725 artigos.

Figura 3: Distribuição de artigos por área de conhecimento da espécie Aloe vera.

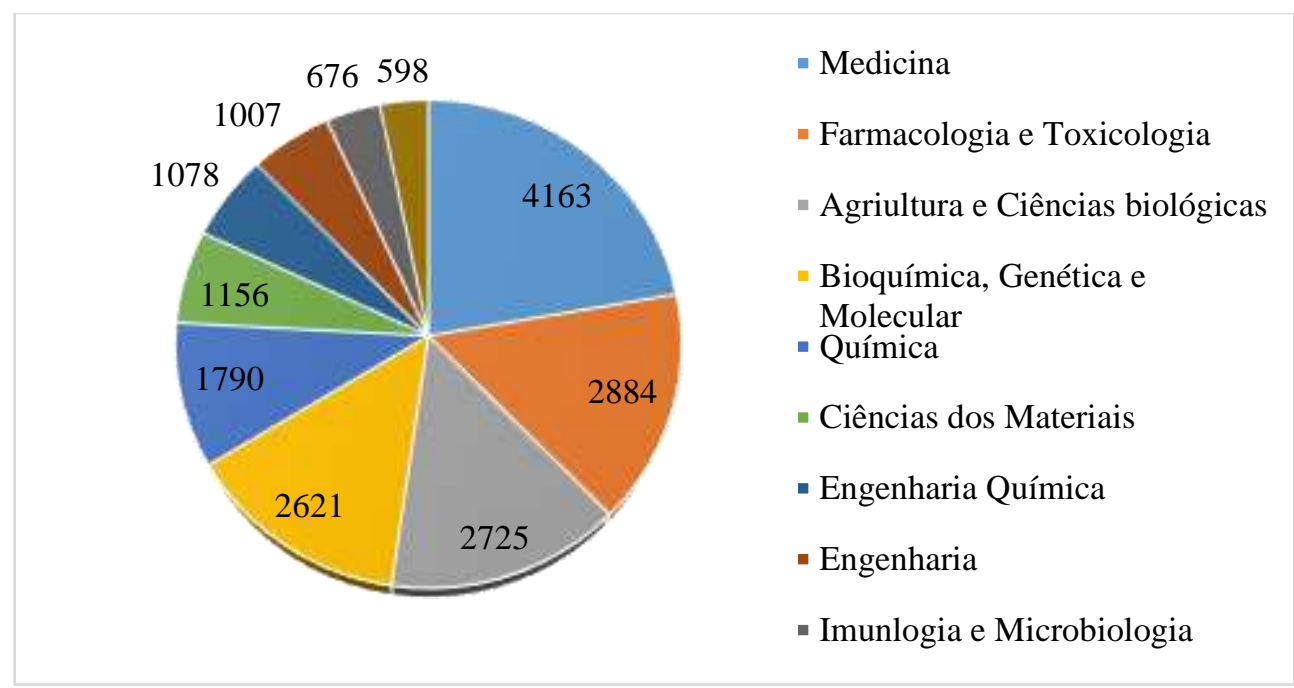

Fonte: Própria (2019)

A planta é muito utilizada com finalidade terapêutica, devido às propriedades antiinflamatórias e antibacterianas de substâncias ativas que estão concentradas tanto no gel quanto na casca das folhas de Aloe vera e que lhes confere muitos benefícios a saúde humana (JOSEPH; RAJ; 2010; NANDAL; BHARDWAJ, 2012). Atrelada à Medicina, está a Farmacologia e Toxicologia, onde a Aloe vera é empregada no estudo de produtos com atividades terapêuticas, assim como na produção de preparações medicinais. Outras grandes áreas foram a Agricultura e Ciências Biológicas.

As análises de documentos de patentes em bases de dados tecnológicas podem ser feitas com a elaboração de indicadores tecnológicos a partir da recuperação das informações nesses sistemas de registros de patentes, com a contagem do número de patentes por países, ano, classificação CIP, dentre outros. Esses documentos de patentes possuem diferentes sistemas de classificação padronizados que as classificam de acordo com o seu conteúdo tecnológico (SCOPEL et al., 2012). Os Estados Unidos configuraram-se como o maior 
detentor de depósito de patentes, com 369 depósitos registrados. Em seguida, a República da Coreia surge como o segundo maior número de depósito com cerca de 210 patentes depositadas. Outros países como o PCT, a China e o EPO também aparecem no ranking (Figura 4).

Figura 4: Distribuição de patentes por países da espécie Aloe vera.

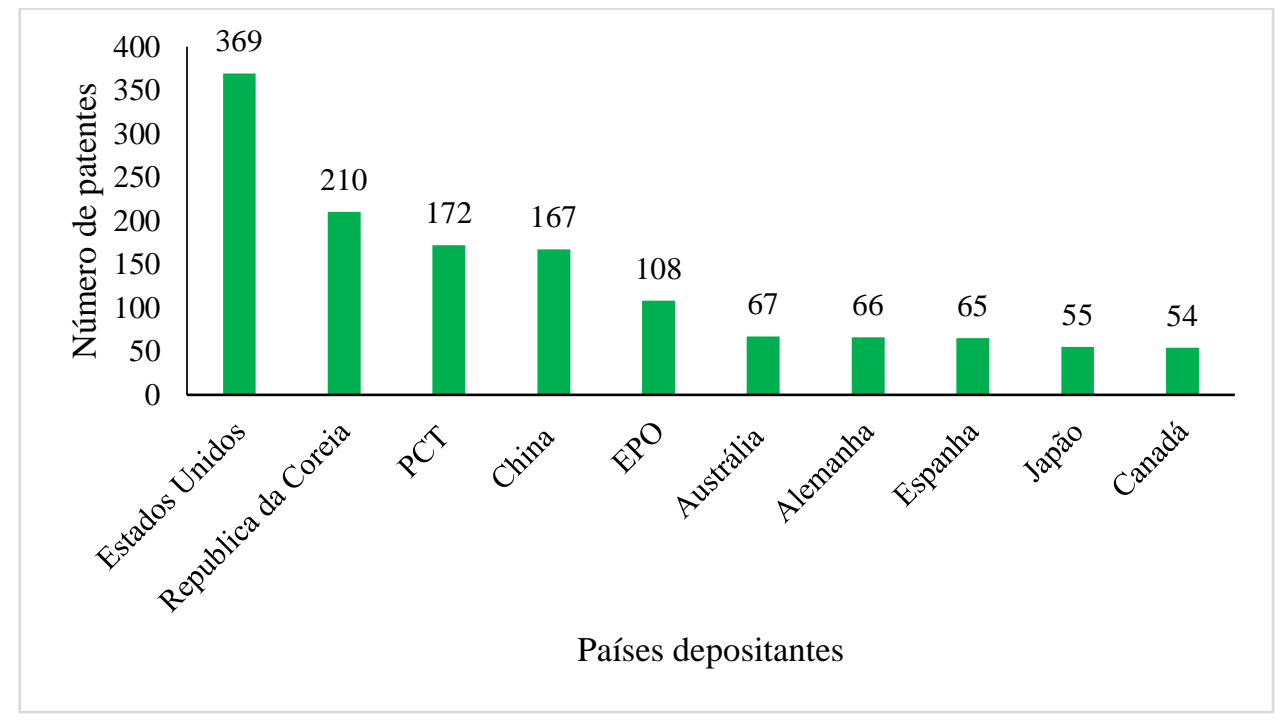

Fonte: Própria (2019)

Os Estados Unidos tem sido referência mundial no depósito de patentes de diversos produtos que vão desde a farmacologia a patentes verdes. A Aloe vera, muito popular no país apresenta um número bastante significativo de patentes depositadas. Este país apresenta forte investimento por parte do governo em projetos de ciência, além de haver cooperações e parcerias entre universidades e empresas privadas visando fomentar o cenário da proteção intelectual e da inovação. Países como a República da Coreia, PCT e China também apresentaram resultados significativos, o que evidencia que investem fortemente em pesquisas tecnológicas com a espécie em questão seja no desenvolvimento de produtos cosméticos, de cunho alimentício ou farmacológico.

O Brasil não aparece no ranking dos dez países que mais desenvolvem tecnologias com a espécie. De acordo com os dados obtidos na base de dados Scopus, o país apresenta 511 artigos científicos publicados envolvendo a Aloe vera. Em relação à produção tecnológica, o país apresenta um número extremamente baixo, levando em conta sua notável produção científica. Isso demonstra que o Brasil não consegue transformar o conhecimento científico produzido em tecnologias.

Ao observar a trajetória anual dos depósitos de patentes, percebe-se que o ano que mais houve depósito foi o ano de 2014 com 99 patentes depositadas, seguido dos anos de 
2013 e 2006 com 94 e 84, respectivamente. Não foi encontrada nenhuma patente no ano de 2017 (Figura 5).

Figura 5: Número de patentes por ano de depósito da espécie Aloe vera.

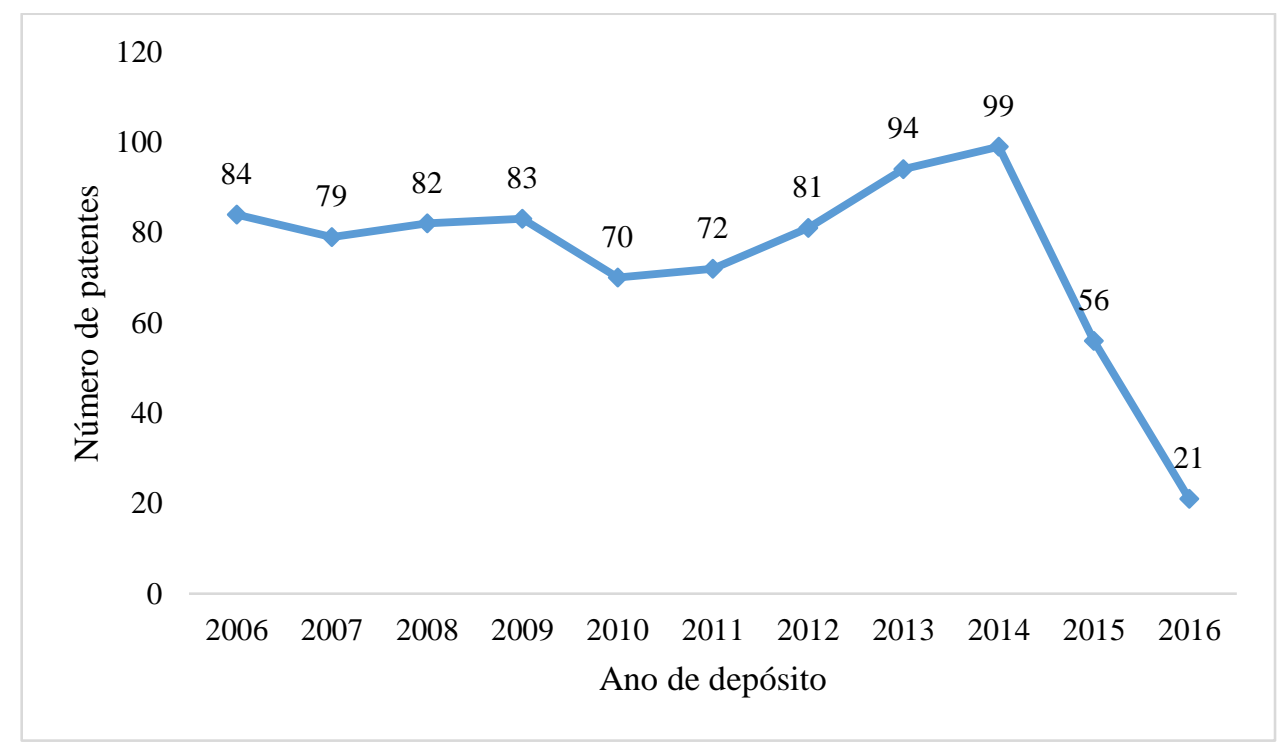

Conforme a Figura 5 constatou-se a trajetória da produção tecnológica por meio de depósitos de patentes. É percebido um crescimento no número de patentes depositadas nos últimos dez anos, o que indica que o interesse tecnológico da Aloe vera vem crescendo substancialmente, até o ano de 2014. A partir de então, a produção tecnológica decresce, até chegar ao mínimo, com 21 patentes depositadas no ano de 2016. Em 2017 não foi registrado nenhuma patente depositada até o presente momento.

Quanto às classificações por CIP das patentes depositadas, observou-se a subclasse $\mathrm{A} 61 \mathrm{~K}$ apresentou o maior número de patentes depositadas, 1.126. Em seguida vêm às subclasses A61Q e A61P com 447 e 294, respectivamente (Figura 6).

Figura 6: Distribuição de patentes por CIP da espécie Aloe vera. 


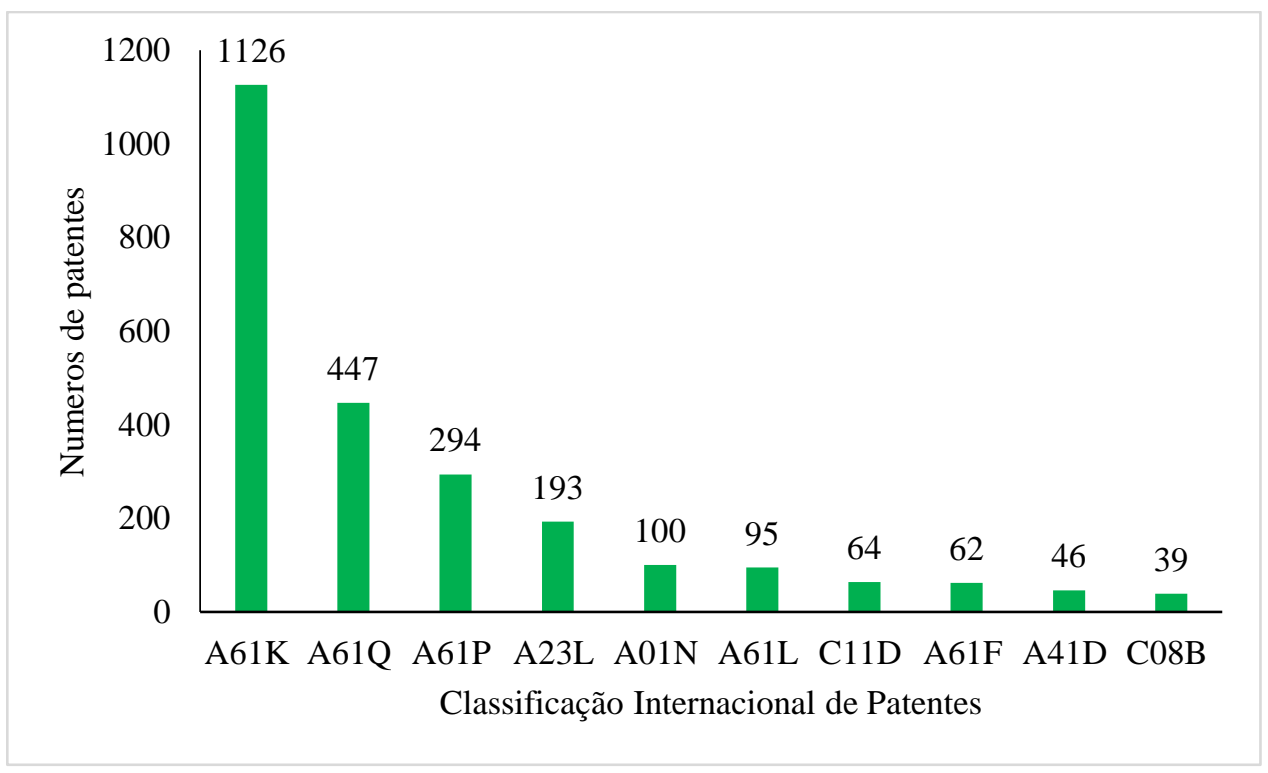

Percebe-se que houve as classes A, que trata de patentes relacionadas a necessidades humanas e C, que trata de Química e Metalurgia. A subclasse em que houve mais classificações foi a A61K, que refere-se a patentes categorizadas com preparações para finalidades médicas, odontológicas ou de toalete. Essa subclasse abrange medicamentos ou outras composições biológicas capazes de prevenir, aliviar, tratar ou curar condições anormais ou patológicas de corpos vivos por meios tais como a destruição de um organismo parasita ou a limitação do efeito da doença ou do estado anormal alterando quimicamente a fisiologia do hospedeiro ou parasita e composições para tratamentos do corpo, em geral destinadas a desodorizar, proteger, embelezar ou cuidar do corpo, a exemplo de cosméticos, dentifrícios, materiais para obturação de dentes.

Já a subclasse A61P abrange a atividade terapêutica de compostos químicos ou preparações medicinais. Dentre as subclasses que apresentam menos patentes categorizadas são A41D e C08B. A primeira subclasse trata de artigos de usos pessoais, A41; enquanto que a subseção D trata especificamente de roupas externas, trajes protetores e/ou acessórios. Já a última subclasse (C08B) abrange patentes desenvolvidas de compostos macromoleculares orgânicos, bem como a sua preparação ou o seu processamento químico; a subclasse B categoriza patentes que tratam de produtos de polissacarídeos e seus derivados.

Constatou-se que a maioria das tecnologias desenvolvidas aqui no Brasil estão categorizadas na subclasse $\mathrm{A} 61 \mathrm{~K}, 11$ patentes depositadas, o que indica que o uso da Aloe vera se dá principalmente na indústria farmacêutica no desenvolvimento de produtos com finalidades médicas e/ou odontológicas. Outras subclasses categorizadas foram a A61L, que descreve patentes cujas tecnologias apresentam aspectos químicos, uso de materiais para 
ataduras ou curativos e almofadas absorventes; A01N que descreve patentes cujos produtos desenvolvidos apresentam substâncias para reduzir o efeito nocivo dos ingredientes ativos para outros organismos (bactérias, fungos etc.) e, apresentou também a subclasse C08B, cujas patentes descrevem produtos de compostos orgânicos macromoleculares, bem como sua preparação ou processamento.

Segundo a Classificação Internacional de Patentes (CIP), a classe A trata de patentes cujas tecnologias são voltadas para as necessidades humanas; a subclasse 61 refere-se às patentes voltadas para higiene em geral. A subclasse $\mathrm{K}$ faz referência a patentes cujas tecnologias tratam de preparações para finalidades médicas, odontológicas ou de toalete. Esta subclasse $(\mathrm{A} 61 \mathrm{~K})$ abrange tanto uma composição, como um processo de preparo da composição ou um processo de tratamento usando essa composição e também medicamentos ou outras composições biológicas capazes de aliviar, tratar ou curar condições anormais ou patológicas de corpos vivos e composições para tratamento do corpo, em geral destinadas a desodorizar, proteger, embelezar ou cuidar do corpo (cosméticos, dentifrícios, materiais para obturação de dentes).

Dentre as treze patentes depositadas no INPI, a primeira refere-se à invenção de Banerjee; Dias; Kalathil (2014), que trata de uma fração empregada na composição de produtos utilizados para os cuidados da pele, cavidade oral e cabelo. O extrato de Aloe vera contém cerca de 60 a $95 \%$ em peso de polissacarídeos com peso molecular no intervalo de 2 a $3 \mathrm{kDa}$; sendo inferior a $5 \%$ de polifenóis, em que os polissacarídeos são hidrolisados por ácido trifluoroacético. Esta patente está classificada como A61K 8/73 (Cosméticos ou preparações similares para higiene pessoal; caracterizado pela composição; contendo compostos orgânicos macromoleculares; Polissacarídeos).

A patente de número 2 trata-se de um produto que possui propriedades antioxidantes e cicatrizantes à base de Aloe barbadensis Miller, o qual é utilizado para aplicação em tratamento de feridas. Atua como cicatrizante, pois há presença de algumas substâncias, como por exemplo, fenóis totais, flavonóis, taninos e saponinas. Esse conjunto de filmes apresentam os seguintes benefícios quando confrontados com os atuais produtos encontrados no mercado, tais como: biodegradáveis, aderente, absorvível pela pele e atóxicos; podem ser umedecidos; não necessitam de curativos secundários e possuem baixo custo sendo classificada como pertencente classe A61K 36/886 (Preparações medicinais que contém materiais de constituição indeterminadas derivados de algas, líquens, fungos, ou plantas, como por 
exemplo medicamentos tradicionais, base de ervas, magnoliophyta (angiospermas); liliopsida (monocotiledôneas), aloaceae (família do Aloe).

A patente de número 3 refere-se a um invento desenvolvido por Danhof (2011), pesquisador da North Texas Medical Associates (US) e trata-se de uma composição farmacêutica incluindo uma combinação de formulações de derivados de Aloe vera para o tratamento do Síndrome de Imunodeficiência Adquirida (AIDS) ou infecção por HIV exposto no documento. A composição inclui um injetável estéril de extrato polymannan, Raidox (antraquinonas e os seus derivados de Aloe diacetil), pó seco por congelação de Aloe vera, suco de A. vera e gel de Aloe. Além disso, contém um ou mais suplementos alimentares que envolvem os ácidos graxos, proteínas, sais minerais e metais, vitaminas, sais, aminoácidos, e outros excipientes aceitáveis pela indústria farmacêutica, podendo também ser utilizado para neutralizar a diarreia crônica, distúrbios digestivos, e perda de peso analisada em alguns pacientes ao longo do tratamento. Essa patente, assim como a anterior, também é classificada com a CIP A61K 36/886.

Outra patente depositada no INPI foi a de Gontijo et al. (2011) com pesquisadores da Universidade Federal de Minas Gerais (UFMG), a invenção apresenta composições farmacêuticas à base de Aloe vera e alginato que são capazes de conservar as células viáveis no interior de sua matriz por um período de 30 dias, sendo conveniente para vários tipos celulares. Os fármacos que contém amoxicilina em sua composição aumentam a viabilidade de osteoblastos (células do tecido ósseo), conservando-os biologicamente ativos. Classificada como A61K 36/296 (Preparações medicinais contendo materiais de constituição indeterminadas derivados de algas, liquens, fungos ou plantas, ou derivados dos mesmos, por ex. medicamentos tradicionais à base de ervas, magnoliophyta (angiospermas), magnoliopsida (dicotiledôneas), berberidaceae (família da berbis).

A patente de número 5 refere-se a uma invenção desenvolvida por Millán; Segura; Gala-Garcia (2008), pesquisadores da Universidade Federal de Minas Gerais, onde trata-se de uma formulação farmacêutica de AIoe vera cujo objetivo é fazer um capeamento, ou seja, um recobrimento direto da polpa dentária com o intuito de induzir o tecido pulpar e na regeneração do tecido dentário, atuando também como matriz para transporte de fármacos e/ou células. Estas formulações desenvolvidas podem existir na forma de pó, pastas, géis, cremes, suspensões, solução, comprimidos, pomadas. Suas misturas podem estar associadas 
ou não a outros fármacos e com a adição ou não de vitaminas, ciclodextrinas, polímeros biodegradáveis e/ou minerais. Está classificada também na subclasse A61K 36/296.

A patente de número 6 de Rosa (2006) trata-se de uma tecnologia de um tônico capilar desenvolvido à base de Aloe vera destinada a cabelos sensíveis e quebradiços, com caspas e dificuldades de crescimento devido aos desgastes naturais e provocados por produtos químicos. Esse produto age no tecido capilar, fazendo com que as enzimas estimulem a vitalidade dos cabelos, restituindo e repondo os aminoácidos perdidos dos fios danificados e quebradiços recuperando a elasticidade natural, higienizando as feridas do couro cabeludo, cicatrizando-as e eliminando as caspas. Esta patente está classificada nas subclasses A61K 36/88 (medicamentos à base de ervas, magnoliophyta (angiospermas), liliopsida (monocotiledôneas).

A patente de número 7 depositada por Queiroz (2006) é uma invenção de curativos usados no tratamento de feridas como diabéticas, úlceras, queimaduras e feridas laceradas. Esses curativos apresentam composições que contém extratos de Aloe vera associados a substâncias como o alginato de cálcio e de sódio e também ao colágeno. Suas propriedades terapêuticas são proporcionadas pela ação do meio aquoso (80-85\%), assim como pelos componentes ativos do extrato de Aloe vera. Também está classificada na subclasse A61K 36/896.

Outra patente depositada no Brasil envolvendo a espécie em questão, indicada na por Queiroz (2006) trata-se de novos curativos autolíticos para o desbridamento (remoção do tecido desvitalizado) de feridas infectadas ou necrosadas. Suas propriedades estão relacionadas à ação autolítica propiciada pelo meio aquoso e por seus componentes sobre as feridas infectadas ou necrosadas. Esta patente está classificada na subclasse A61K 36/896.

A patente de número 9 depositada na base tecnológica brasileira foi a do pesquisador Eng et al. (2005), esta refere-se a uma invenção de uma luva em que as superfícies internas da mesma possuem uma película que contém água, glicerol e um extrato botânico. É classificada como A01N 25/34 (conservação de corpos de seres humanos ou animais ou plantas ou partes dos mesmos; biocidas, desinfetantes, pesticidas; herbicidas, folhas não mencionadas em qualquer outro subgrupo deste grupo principal).

A patente de número 10 cuja tecnologia foi desenvolvida por Van Weerelt (2003) trata-se do uso do sumo de Aloe vera como soluto numa solução tendo como solvente hidrolatos de materiais orgânicos e inorgânicos. Esta solução é usada como na área 
farmacêutica, bioquímica e industrial, e contém princípios ativos ou fármacos do sumo de Aloe vera e dos hidrolatos mencionados. Está classificada também na CIP A61K 36/886.

A patente de número 11 depositada aqui no Brasil envolvendo a espécie Aloe vera foi desenvolvida por Dijk, Goedbloed; Koumans (2002), referindo-se a uma composição contendo polissacarídeos negativamente carregados derivados da Aloe vera e um processo para preparar essa composição de matéria por subfracionamento do extrato da planta. Esta composição é útil como um suplemento alimentar, para uso em cuidado pessoal e em cosméticos, especialmente para prevenir uma infecção com as bactérias. Ela está classificada na subclasse C08B 37/00 (preparações de polissacarídeos não abrangidos pelos grupos e seus derivados).

A patente de número 12 é deposita e desenvolvida por Fávere et al. (2002) e trata-se de uma composição farmacêutica contendo quitosana e Aloe vera para uso oral em humanos com o objetivo de se obter alternativas para redução de colesterol. Está classificada na subclasse A61K 31/722 (preparações medicinais contendo ingredientes ativos orgânicos, carboidratos, derivados dos mesmos, polissacarídeos, tendo mais de cinco radicais sacarídeos ligados entre si por ligações glicosídicas; seus derivados (éteres, ésteres, glicanos e quintana).

A última patente depositada foi desenvolvida por Coelho (1995) e trata-se da invenção de uma composição com ação depilatória, preparada com uma substância que possui inúmeras propriedades regenerativas, lubrificantes, nutritivas e umectantes, tendo como demais componentes a cera de abelha, vaselina sólida, essência de mel e a própria Aloe Vera. Está classificada na subclasse A61K 7/155.

\section{Conclusões}

Obteve-se um panorama do desenvolvimento científico e tecnológico da espécie Aloe vera. Com a prospecção científica, conclui-se que, o país que mais produziu ciência envolvendo a babosa foi à Índia com 2.936 artigos, seguida dos Estados Unidos. O Brasil ocupou a $5^{\text {a }}$ posição no ranking. Quanto ao desenvolvimento científico ao longo dos últimos 10 anos, observou-se um crescimento gradual. Em relação às áreas de maior interesse destacaram-se a medicina e a farmacologia/toxicologia.

Com a prospecção tecnológica realizada, conclui-se que os Estados Unidos é o país com o maior grau de inovação tecnológica envolvendo a planta em questão, enquanto que o Brasil não apareceu no ranking, o que indica que o país apresenta um baixo grau de inovação 
tecnológica dentro da temática da Aloe vera, apontando para um fraco investimento na produção de tecnologias envolvendo a espécie. Quanto ao desenvolvimento tecnológico nos últimos 10 anos, a produção de tecnologias vem decrescendo substancialmente, revelando uma falta de interesse tecnológico na espécie. Quanto à CIP, a subclasse mais categorizada foi a $\mathrm{A} 61 \mathrm{~K}$, apontando para o maior uso da $A$. vera no desenvolvimento de produtos com finalidades médicas e odontológicas.

A partir desta pesquisa foi possível perceber que foram identificadas diversas atividades com fins farmacológicas que a Aloe vera apresenta o que corrobora com estudos que mostram o elevado potencial de suas propriedades no tratamento doenças, especialmente quando se trata de ações cicatrizantes, antioxidantes e antimicrobianas.

\section{Agradecimentos}

Ao Grupo de Pesquisa cadastrado no Conselho Nacional de Desenvolvimento Científico e Tecnológico (CNPq) em Alimentos, Química, Agronomia e Recursos Hídricos (AQARH).

\section{Referências}

BACH, D. B.; LOPES, M. A. Estudo da viabilidade econômica do cultivo da babosa (Aloe vera L.). Ciênc. Agrotec., Lavras, v. 31, n. 4, p. 1136-1144, jul./ago., 2007.

BANERJEE, G.; DIAS, P. M.; KALATHIL, R. UNILEVER PLC (a company registered in England and Wales under company no. of Unilever House, 100 Victoria Embankment, London Greater London EC4Y 0DY, 41424, GB). 2014.

CAPES - Coordenação de Aperfeiçoamento de Pessoal de Nível Superior. Scopus. 2016. Disponível em: https://www.periodicos.capes.gov.br/images/documents/Scopus_Guia\%20de\%20refer\%C3\% AAncia\%20r\%C3\%A1pida_10.08.2016.pdf. Acesso em: 13 jan. 2019.

COELHO, D. O. Composição para cera depilatória. PI 9504105-2 A2. Classificação: A61K 7/06. 1995.

DANHOF, I. E. Tratamento de síndrome de imunodeficiência adquirida (aids) com propriedades antivirais de Aloe vera L. Patente. 2011.

FÁVERE, V. T.; LARANJEIRA, M. C. M.; PEDROSA, R.C.; PEDROSA, R. C.; GEREMIAS, R. Composição farmacêutica contendo cloridrato de quitosana e Aloe vera. PI 0202748-8 A2. Patente. 2002.

GIL, A. C. Como elaborar projetos de pesquisa. 4. ed. São Paulo: Atlas, 2002. 
GONTIJO, S. M. L.; GAlA GARCIA, A.; SINISTERRA, R. D.; CORTÉS, M. E. . Composições Farmacêuticas à base de Aloe vera e alginato e seus usos. 2011. Patente.

JOSEPH, B.; RAJ, S. J. Pharmacognostic and Phytochemical properties of Aloe vera linn - an overview. International Journal of Pharmaceutical Sciences Review and Research. Bangalore, v. 4, n. 2, p. 106-110, 2010.

MILLÁN, R. D. S.; SEGURA, M. E. C.; GALA-GARCIA, A. Formulação farmacêutica à base de Aloe vera para capeamento direto em polpa dentária e como matriz para transporte de fármacos e/ou células. Patente. PI 0802009-4 A2. (2008).

NANDAL, U.; BHARDWAJ, R.L. Aloe vera for human nutrition, health and cosmetic use A review. International Research Journal of Plant Science. Chicago, v. 3, n. 3, p. 38-46, 2012.

PARENTE, L. M. L.; CARNEIRO, L. M.; TRESVENZO, L. M. F.; GARDIN, N. E. Aloe vera: características botânicas, fitoquímicas e terapêuticas Aloe vera. Arte Médica Ampliada v. 33, n. 4, 2013.

PATROCÍNIO, A. F.; MANCILHA, M. Aloe vera - abordagem técnica. In: Synthon Especialidades. Sorocaba/SP. 2012. Anais... São Paulo: 2012.

PEREIRA, S. A.; MENDONÇA, M. S.; BARBALHO, C. R. S.; ALENCAR, M. S. M.; SOUZA, C. M. Prospecção científica e tecnológica do gênero Jatropha (Euphorbiaceae). Cad. Prospec., Salvador, v. 8, n. 2, p. 355-364, abr.jun. 2015.

QUEIROZ, M. M. F. Curativo tópico a base de Aloe vera (babosa). PI 0602852-7 A2. 2006.

ROSA, I. Tônico capilar natural alôe vera. PI 0604689-4 A2. A61K 36/88; A61P 17/08; A61G 5/00. Patente. 2006.

SOTILLI, C. M. Utilização de Aloe vera na promoção da saúde e seus riscos em potencial pelo uso Indiscriminado, 2015.

DIJK, W. V.; GOEDBLOED, A. F.; KOUMANS, F. J. R. Composição compreendendo polissacarídeos deriváveis de Aloe vera, extrato nag-25, extrato ultrafiltrado de aloe, seus processos de preparação, suas formas de dosagens, e seus usos. PI 0215394-7 B1. 2002. Patente.

ENG, A. H. et al. Luva com revestimento agradável ao tato e método de fabricação. PI 0520711-8 A2. Patente. 2005.

WHO - World Health Organization. WHO Monographs on selected medicinal plants, v. 1. Geneva: WHO Publications, 1999.

WIPO - World Intellectual Property Organization. About WIPO. Disponível em: http://www.wipo.int/about-wipo/en/. Acesso em: 18 fev. 2019. 